\title{
'Candidatus Midichloria mitochondrii', an endosymbiont of the tick Ixodes ricinus with a unique intramitochondrial lifestyle
}

\author{
Davide Sassera, ${ }^{1}$ Tiziana Beninati, ${ }^{2}$ Claudio Bandi, ${ }^{1}$ Edwin A. P. Bouman, ${ }^{3}$ \\ Luciano Sacchi, ${ }^{4}$ Massimo $\mathrm{Fabbi}^{5}$ and Nathan $\mathrm{Lo}^{2}$
}

Correspondence

Nathan Lo

nathan@usyd.edu.au

\author{
'Dipartimento di Patologia Animale, Igiene e Sanità Pubblica Veterinaria, Università degli studi \\ di Milano, 20133 Milan, Italy \\ ${ }^{2}$ School of Biological Sciences, The University of Sydney, New South Wales 2006, Australia \\ ${ }^{3}$ Biology Centre, Institute of Parasitology, Academy of Sciences of the Czech Republic, \\ Branišovská 31, 37005 České Budějovice, Czech Republic \\ 4,5Dipartimento di Biologia Animale, Università di Pavia, Piazza Botta $9^{4}$ and Sezione \\ Diagnostica di Pavia, Istituto Zooprofilattico Sperimentale della Lombardia e dell'Emilia \\ Romagna "Bruno Ubertini"5, 27100 Pavia, Italy
}

\section{INTRODUCTION}

The genera and the families of the order Rickettsiales have recently been reorganized and redescribed by Dumler et al. (2001). Based on this taxonomic revision, this order now encompasses two coherent monophyletic groups at the family rank: the Rickettsiaceae and the Anaplasmataceae. The six genera of the order also form well-defined monophyletic clusters within the two families: Rickettsia and Orientia within the Rickettsiaceae and Anaplasma, Wolbachia, Ehrlichia and Neorickettsia within the Anaplasmataceae. The family Anaplasmataceae might include a fifth genus ('Candidatus Xenohaliotis') and a further main branch has been recognized which might represent a third family in the order Rickettsiales, the Holosporaceae (Garrity et al., 2004; but see Lee et al., 2005). All of these bacteria share a common

\section{Abbreviation: EM, electron microscopy.}

The GenBank/EMBL/DDBJ accession number for the gyrB gene sequence of 'Candidatus Midichloria mitochondrii' is AM159536. characteristic: they have never been cultured outside eukaryotic cells and are thus regarded as obligately intracellular. Different host types have been described for these bacteria, ranging from vertebrates to nematodes (Bandi et al., 1998; Parola, 2004), but several species in both families are associated with arthropods, particularly ticks.

Bacterial 16S rRNA gene sequences obtained recently during analysis of ticks and amoebae showed high similarity to $16 \mathrm{~S}$ rRNA gene sequences from members of the Rickettsiales (Fritsche et al., 1999; Goddard et al., 2003; Parola et al., 2003; Beninati et al., 2004; Mediannikov et al., 2004). In particular, Fritsche et al. (1999) obtained almost complete 16S rRNA gene sequences from the symbionts of two strains of Acanthamoeba spp. and showed that these sequences formed a new lineage within the Rickettsiales. According to Fritsche et al. (1999), this lineage could represent a new genus and possibly a new family of this order. Subsequently, bacterial 16S rRNA gene sequences showing similarity (90-92\%) to 
those from the endosymbionts of Acanthoamoeba spp. were obtained from various tick species: Haemaphysalis wellingtoni (Parola et al., 2003), Ixodes ricinus (Sanogo et al., 2003; Beninati et al., 2004) and Ixodes persulcatus (Mediannikov et al., 2004). Phylogenetic analyses of these sequences revealed the existence of a novel clade within the order Rickettsiales (Beninati et al., 2004). Moreover, short 16S rRNA gene sequences (376-947 bp) that cluster within this novel clade have also been obtained from ticks (Sanogo et al., 2003; Schabereiter-Gurtner et al., 2003; Goddard et al., 2003), from humans (Mediannikov et al., 2004) and from microbial mats (O. Sanchez, unpublished GenBank submissions AJ871029 and AJ871030).

Most of the above tick-associated 16S rRNA gene sequences were obtained in the context of PCR surveys without any specific microscopical observations. One exception was the study by Beninati et al. (2004) that reported electron microscopy (EM) observations of an intracellular bacterium as well as in situ hybridization and extensive sequencing of $16 \mathrm{~S}$ rRNA gene sequence clones (see also Sacchi et al., 2004). This symbiont of $I$. ricinus has provisionally been designated IricES1 (Beninati et al., 2004). IricES1 has been observed in the ovaries of females of I. ricinus with $100 \%$ prevalence, while lower prevalence is reported in male ticks (Lo et al., 2006). In females, the bacterium inhabits the cytoplasm of ovarian cells and possesses the peculiar ability to invade and destroy the host's mitochondria. IricES1 is thus presently the only member of the novel clade of the Rickettsiales for which detailed ultrastructural observations are available in addition to information on its distribution within the host species.

In summary, molecular evidence is available which indicates the existence of a novel major clade within the order Rickettsiales. We believe this clade deserves more attention as well as formal taxonomic description. The information available for the IricES1 symbiont of I. ricinus now provides the opportunity for the proposal of a new genus and species name, while future studies will address the issue of whether a new family should be created in the order Rickettsiales.

This paper reports (i) partial sequencing and phylogenetic analysis of gyrB, the gene encoding DNA gyrase subunit B, from IricES1, (ii) phylogenetic analyses of $16 \mathrm{~S}$ rRNA and gyrB gene sequences and (iii) a summary of results of previous studies on IricES1, including EM, in situ hybridization and prevalence studies. In view of the fact that cultivation of IricES1 has not yet been achieved, we propose the classification of the bacterium as 'Candidatus Midichloria mitochondrii'.

\section{METHODS}

Cloning and sequencing of the gyrB gene. An adult female tick collected in Berlin, Germany, was fed on a hamster and allowed to deposit eggs. DNA was extracted from five pooled eggs using a DNeasy Kit (Qiagen). To control for the presence of bacteria other than the intramitochondrial symbiont, PCR and cloning of $16 \mathrm{~S}$
rRNA genes was performed as described in Beninati et al. (2004). This experiment indicated that the eggs were infected only by the intramitochondrial symbiont. The $\operatorname{gyr} B$ gene was then amplified with the universal bacterial primers gyrBAUP 2 and gyrBBNDN (Santos \& Ochman, 2004). Amplifications were performed in $20 \mu \mathrm{l}$ buffer $\left[10 \mathrm{mM}\right.$ Tris/HCl (pH 8.3), $50 \mathrm{mM} \mathrm{KCl,} 1.5 \mathrm{mM} \mathrm{MgCl}_{2}$, $0.001 \%$ gelatin] with $0 \cdot 2 \mathrm{mM}$ each deoxynucleoside triphosphate, 20 pmol each primer, $1 \mathrm{U}$ Taq polymerase (Perkin Elmer) and $1 \mu \mathrm{l}$ DNA sample. The conditions for the PCR on a PTC-100 thermal cycler (Peltier) were as follows: 2 min denaturation at $94{ }^{\circ} \mathrm{C}$; then five touchdown cycles (every cycle with $1{ }^{\circ} \mathrm{C}$ lower annealing temperature) $1 \mathrm{~min}$ at $94^{\circ} \mathrm{C}, 1 \mathrm{~min}$ at $55^{\circ} \mathrm{C}\left(-1^{\circ} \mathrm{C}\right.$ per cycle $), 1 \mathrm{~min}$ at $72{ }^{\circ} \mathrm{C}$; then 25 cycles with $1 \mathrm{~min}$ at $94^{\circ} \mathrm{C}, 1 \mathrm{~min}$ at $50^{\circ} \mathrm{C}, 1 \mathrm{~min}$ at $72^{\circ} \mathrm{C}$ and final steps of $6 \mathrm{~min}$ at $72{ }^{\circ} \mathrm{C}, 5 \mathrm{~min}$ at $15^{\circ} \mathrm{C}$.

The PCR product was visualized on an agarose gel, purified using a Nucleospin Extract purification kit (Macherey Nagel) and cloned using a pGEM-T Easy Vector System cloning kit (Promega). The inserts from four colonies were sequenced using $\mathrm{ABI}$ technology, initially with the primers T7 and SP6. A consensus from the sequences of the four clones was obtained. Eight additional primers were successively designed by a walking approach (Iric-GyrB-F1 GTTGATGGTGTTGCCGTTAAG; Iric-GyrB-R1 GATTTGCCATATCGAGATCAC; Iric-GyrB-F2 CTCTGTGGTTAATGCATTGTCG; Iric-GyrB-R2 CTTCTACAAGGAAGAGCTCG; Iric-GyrB-F3 GAGTGACAAAGATATTTCGGC; Iric-GyrB-R3 TTACTTCCGTTCCTCTCTTAC; Iric-GyrB-F4 GACAATTTATCAAAGTGGCTTG; Iric-GyrB-R4 CGCTCAACATAACTATTGAAGC). These primers were used on the product of the gyrBAUP $_{2}$ and gyrBBNDN 1 primers in order to generate doublestranded sequence directly from the PCR product obtained from four different tick samples.

Phylogenetic analyses of 16S rRNA and gyrB gene sequences. The $16 \mathrm{~S}$ rRNA gene sequence of 'Candidatus M. mitochondrii' was subjected to BLAST analysis and closely related, nearly full-length sequences were aligned, taking into account secondary structure, at the Ribosomal Database Project website (Cole et al., 2003). Phylogenetic analysis was performed under Bayesian Inference criteria using the MrBayes program (Huelsenbeck \& Ronquist, 2001). Parameters for the selected model of substitution were estimated from the data using MrModeltest (Nylander, 2002). A total of 15000 trees were obtained (ngen $=1500000$, samplefreq $=100$ ) and the first 5000 of these were considered as the 'burn in' and discarded. A $50 \%$ majority-rule consensus tree of the remaining 10000 trees, including branch lengths (savebrlens=yes) was produced. Three different replications of these analyses were performed. A second analysis was performed comparing shorter $16 \mathrm{~S}$ rRNA gene sequences (376-947 bp) that had been determined to be closely related to 'Candidatus M. mitochondrii' by BLAST analysis.

For the $\operatorname{gyrB}$ gene, relevant sequences were aligned with the sequence obtained for 'Candidatus M. mitochondrii' following BLAST searches. Phylogenetic analyses of the $g y r B$ gene were performed at the amino acid level due to the high level of nucleotide divergence (61-65\% similarity) between 'Candidatus M. mitochondrii' and other taxa. GyrB amino acid sequences were aligned with sequences from various members of the Alphaproteobacteria using CLUSTAL_X (Thompson et al., 1997). Minor editing was done manually. A 535-amino acid alignment was used for phylogenetic analyses under the maximum-likelihood Quartet Puzzling criteria using the TreePuzzle 5.2 program (Strimmer \& Haeseler, 1996).

Electron microscopy. Adult female ticks collected in České Budějovice (Czech Republic) were fed on guinea pigs until engorgement (3-5 days). Ovaries were dissected out in saline solution and fixed in $0 \cdot 1 \mathrm{M}$ cacodylate buffer $(\mathrm{pH} 7 \cdot 2)$ containing $2 \cdot 5 \%$ glutaraldehyde for $3 \mathrm{~h}$ at $4{ }^{\circ} \mathrm{C}$. The samples were washed in the same buffer and then post-fixed in $1 \% \mathrm{OsO}_{4}$ in the same buffer for $1.5 \mathrm{~h}$ at 
$4{ }^{\circ} \mathrm{C}$. All samples were dehydrated in an ethanol series and embedded in Epon 812 . Semithin sections $(1 \mu \mathrm{m})$ for light microscopy were stained with $0.5 \%$ toluidine blue. Thin sections $(80 \mathrm{~nm})$ were stained with uranyl acetate and lead citrate and examined under a transmission electron microscope (EM900; Zeiss).

\section{RESULTS AND DISCUSSION}

BLAST searches involving the 'Candidatus M. mitochondrii' $16 \mathrm{~S}$ rRNA gene sequence revealed the presence of a number of closely related sequences of uncharacterized bacteria obtained from various tick species, amoebae, humans and microbial mats. When compared with the sequence of 'Candidatus M. mitochondrii', similarities ranged from $90 \%$ (GenBank accession number AF493952 derived from Ixodes persulcatus) to $99 \%$ (a different sequence from $I$. ricinus, GenBank accession number AF525482, possibly the same bacterium). The overall level of $16 \mathrm{~S}$ rRNA gene sequence divergence among these sequences is comparable to that observed among species of the same genus or even genera of the same family within the Rickettsiales. For example, within the genus Ehrlichia, 16S rRNA gene sequence similarities range from 96 to $98 \%$. Within the family Anaplasmataceae, the level of similarity between different genera varies from $\sim 83$ to $\sim 90 \%$.

Phylogenetic comparisons between the 'Candidatus $\mathrm{M}$. mitochondrii' $16 \mathrm{~S}$ rRNA gene sequence and near full-length sequences $(>1200 \mathrm{bp})$ in the databases revealed the existence of a strongly supported monophyletic group containing various unclassified bacteria from ticks and from Acanthamoeba spp. (Fig. 1). These results are in agreement with previous studies (Fritsche et al., 1999; Parola et al., 2003; Beninati et al., 2004; Mediannikov et al., 2004) in which the bacteria of this group were found to be the sister group of the family Anaplasmataceae (comprising the genera Anaplasma, Ehrlichia, Neorickettsia and Wolbachia). Separate analyses, including partial 16S rRNA gene sequences $(<1000 \mathrm{bp})$, showed that this phylogenetic branch includes other sequences obtained from ticks, humans and a microbial consortium (Fig. 2). 'Candidatus M. mitochondrii' is closely related to an uncharacterized bacterium from the tick $H$. wellingtoni (Figs 1 and 2). Since these ticks are distantly related (Black \& Piesman, 1994), this suggests that 'Candidatus M. mitochondrii' and its relatives may undergo horizontal transfer.

The gyrB gene sequence obtained is 1432 bp long with a DNA G $+\mathrm{C}$ content of $39 \cdot 4 \mathrm{~mol} \%$. BLAST analysis showed that the sequence is most closely related to sequences from the genera Anaplasma, Ehrlichia, Wolbachia, Neorickettsia and Rickettsia. Sequences of the gyrB gene from each of these genera were downloaded from the databases and aligned with the sequence from 'Candidatus M. mitochondrii'. Phylogenetic inference from gyrB gene sequence alignments clearly showed that 'Candidatus M. mitochondrii' is placed within the Alphaproteobacteria as a divergent lineage most closely related to members of the family Anaplasmataceae (Fig. 3). This placement was slightly different to its position within the 16S rRNA gene sequence tree (Fig. 1), where it was found outside the family Anaplasmataceae. This may be due to the fact that fewer gyrB gene sequences are available compared with $16 \mathrm{~S}$ rRNA gene sequences.

Electron microscopy of $I$. ricinus collected in the Czech Republic showed that 'Candidatus M. mitochondrii' is found within the mitochondria of the ovaries of these ticks (Fig. 4). These results are in agreement with previous EM studies of $I$. ricinus collected in England (Lewis, 1979), Switzerland (Zhu et al., 1992) and Italy (Beninati et al., 2004; Sacchi et al., 2004).

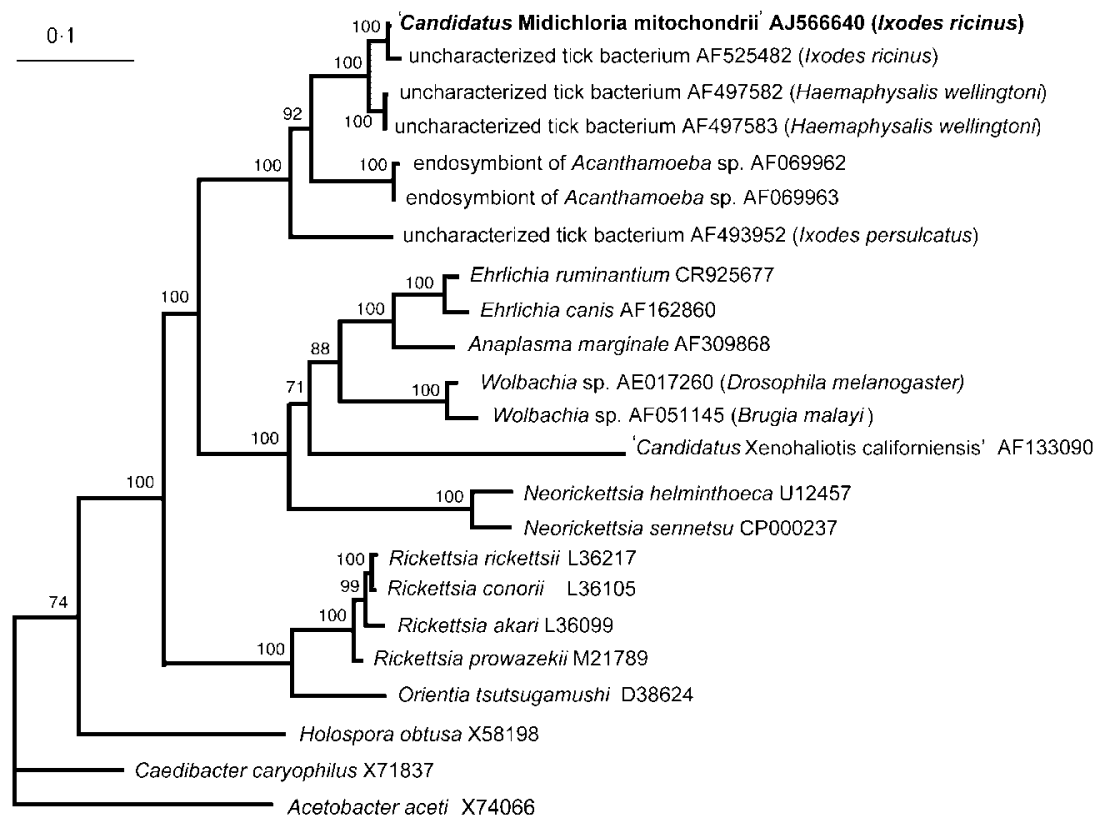

Fig. 1. Phylogenetic tree based on near fulllength 16S rRNA gene sequences (>1200 bp) showing the position of 'Candidatus M. mitochondrii' and selected members of the Rickettsiales. The tree was generated using MrBayes. The GenBank accession number for each sequence is indicated. Numbers adjacent to each node represent the posterior probability values. Acetobacter aceti (Rhodospirillales) was included as an outgroup. Additional analyses in which other Alphaproteobacteria were included as outgroups generated trees showing the same overall topology. Host species are shown in parentheses, where relevant. Bar, $0 \cdot 1$ inferred substitutions per site. 


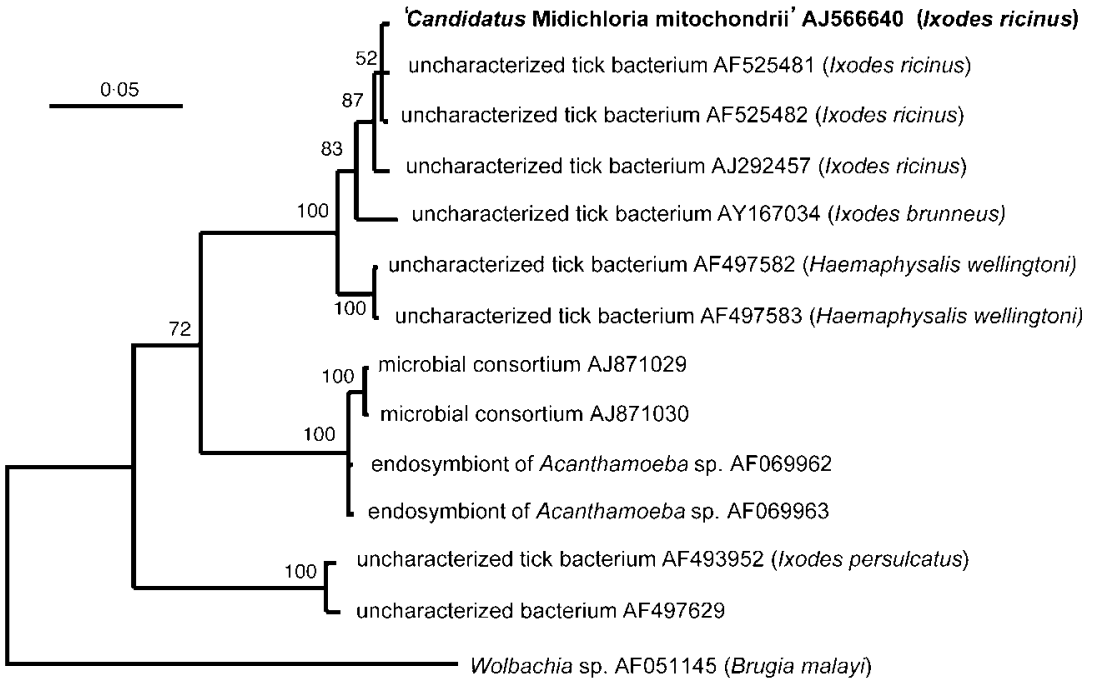

Fig. 2. Phylogenetic tree showing the position of 'Candidatus M. mitochondrii' in relation to closely related and short uncharacterized sequences. The tree is based on a $524 \mathrm{bp}$ $16 \mathrm{~S}$ rRNA gene sequence alignment and was generated using MrBayes. The GenBank accession number for each sequence is indicated. Numbers above each node represent the posterior probability values. Wolbachia sp. from Brugia malayi was included as an outgroup. Additional analyses in which other Alphaproteobacteria were included as outgroups generated trees showing the same overall topology. Host species are shown in parentheses. Bar, 0.05 inferred substitutions per site.
In summary, the information already available in the literature and in databases, as well our new results, clearly show that a further phylogenetic branch exists within the order Rickettsiales. This branch may deserve to be elevated at the family rank when further data is obtained, as already suggested (Fritsche et al., 1999). We believe the information currently available for one member of this clade, IricES1, meets the criteria required for the description of new genera and species (for uncultured bacteria, see Murray \& Stackebrandt, 1995; see also Zeigler, 2003). In brief, the information available is (i) sequences of two genes (Beninati et al., 2004; this study), (ii) localization in the host tissues by in situ hybridization and electron microscopy (Beninati et al., 2004; this study), (iii) detailed ultrastructural observations (Sacchi et al., 2004), (iv) prevalence studies throughout
European and North African populations of the host species (Lo et al., 2006) and (v) PCR evidence for efficient vertical transmission (Lo et al., 2006).

\section{Description of 'Candidatus Midichloria mitochondrii'}

'Candidatus M. mitochondrii' appears in EM observations (Lewis, 1979; Zhu et al., 1992; Sacchi et al., 2004) as a Gramnegative bacterium with a bacillus shape of $\approx 0.45 \mu \mathrm{m}$ in diameter and $\approx 1.2 \mu \mathrm{m}$ in length. This bacterium is observed within various cell types (lumenal cells, funicular cells and oocytes) of the ovary of the hard tick I. ricinus (Ixodidae). In all of the above cell types, the bacteria are observed free in the cytoplasm or included in a host-derived

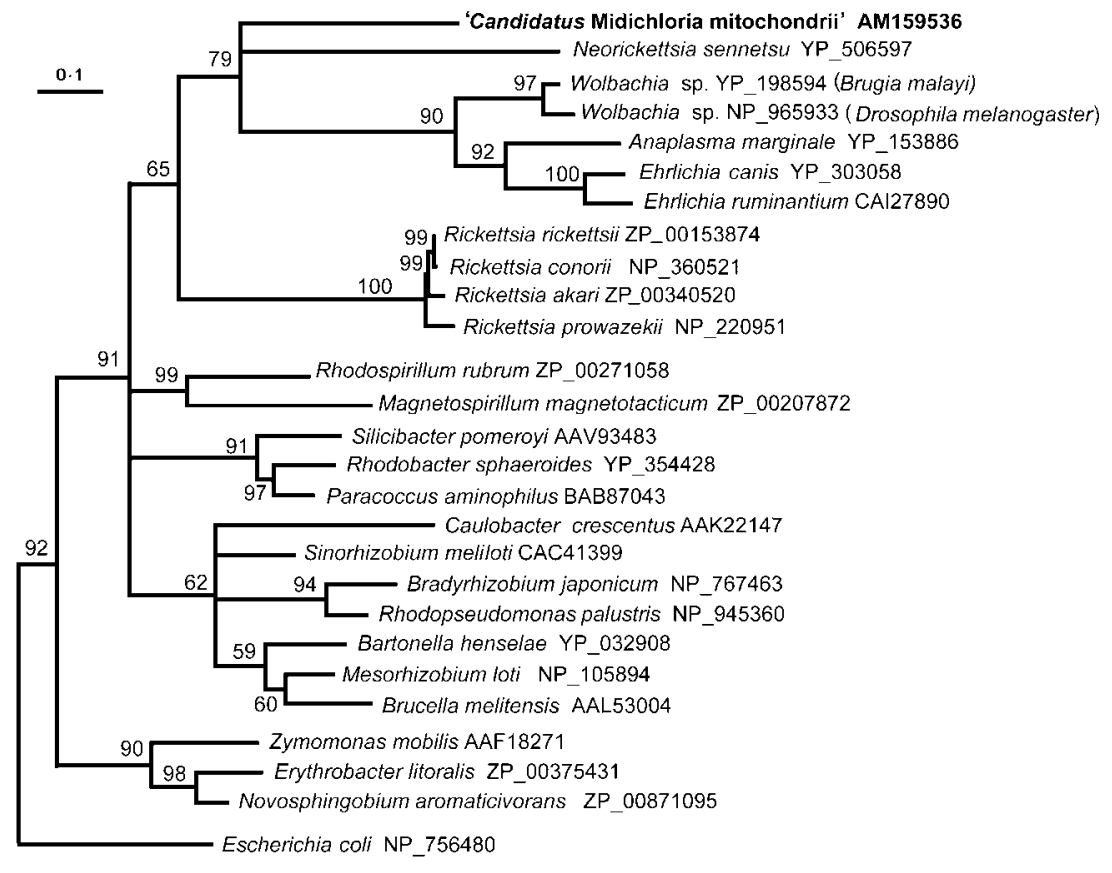

Fig. 3. Phylogenetic comparison of the $g y r B$ gene sequence of 'Candidatus $M$. mitochondrii' with those from other members of the Alphaproteobacteria. The tree was constructed on a 535-amino acid alignment using TreePuzzle 5.2 with the WAG model of substitution, assuming among-site variation (gamma distribution, 4 rates). A tree estimated with the JTT model of substitution showed the same topology at the level of the main branches. For other parameters, defaults were used. GenBank accession numbers are indicated for each sequence. The host species is indicated in parentheses where relevant. Numbers above each node are Quartet Puzzling support values. Escherichia coli is included as an outgroup. Additional analyses in which various other Proteobacteria were used as outgroups generated trees with the same overall topology. Bar, 0.1 inferred substitutions per site. 


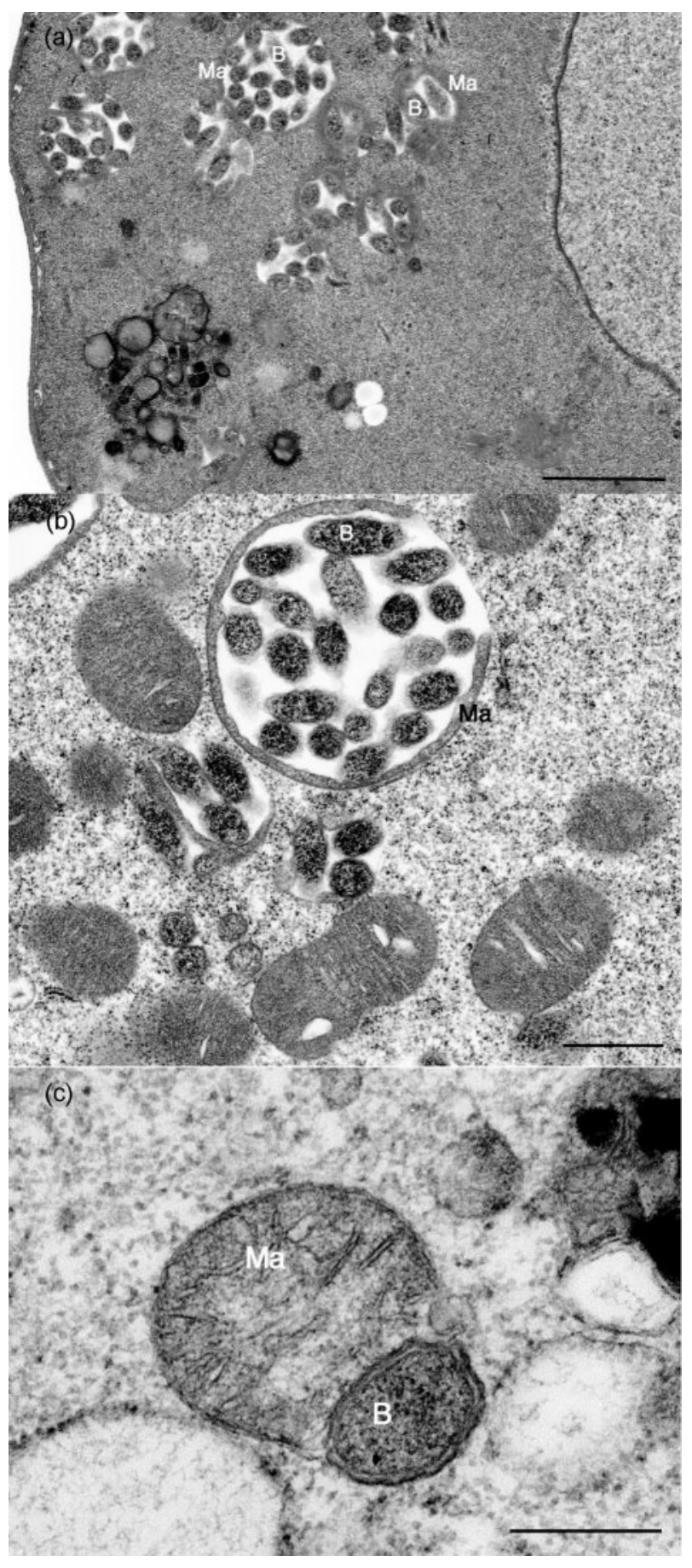

Fig. 4. Electron micrographs of ovarian cells of $I$. ricinus containing 'Candidatus M. mitochondrii' (B) within intact or degraded mitochondrial matrix (Ma). Bars, 2.4 $\mu \mathrm{m}(\mathrm{a}), 1 \cdot 2 \mu \mathrm{m}$ (b) and $0.45 \mu \mathrm{m}$ (c).

membrane. In addition, in luminal cells and oocytes, the bacterium is also observed within the mitochondria, in the periplasmic space between the two membranes of these organelles. As the development of the oocyte proceeds, the bacteria appear to consume the inner part of the mitochondria and multiply therein. The mitochondrial matrix is reduced as a result and some mitochondria appear as sacs full of bacteria (Sacchi et al., 2004). Different numbers of bacteria have been observed within the mitochondria, from a single bacterium to over 20. Despite the high number of mitochondria consumed by the bacterium, the eggs of the tick develop normally. In situ hybridization with probes designed to target specific $16 \mathrm{~S}$ rRNA gene regions resulted in the staining of only ovarian cells in female ticks (Beninati et al., 2004). In male ticks, there is only PCR evidence for the presence of the bacterium (Lo et al., 2006). The symbiont appears to be ubiquitous in the females of $I$. ricinus across its distribution (prevalence, $100 \%$ ), while a significantly lower prevalence is observed in males $(44 \%)$. In males that test positive by PCR, the bacterial load also appears lower compared with females (Lo et al., 2006). Evidence for efficient vertical transmission of the bacterium has been reported based on PCR screening of eggs. Sequencing of the $16 \mathrm{~S}$ rRNA and gyrB genes from ticks from 11 different countries from across the distribution of $I$. ricinus showed a low level of variability in both genes. One substitution in 380 bases was found in the 16S rRNA gene sequence and two substitutions in 519 bases were found in the gyrB gene sequence (Lo et al., 2006).

In accordance with the guidelines of the International Committee of Systematic Bacteriology, unculturable bacteria should be classified as Candidatus (Murray \& Stackebrandt, 1995). Thus we propose the name 'Candidatus Midichloria mitochondrii' for the novel bacterium. The genus name Midichloria (mi.di.chlo' ria. N.L. fem. n.) is derived from the midichlorians, organisms within the fictional Star Wars universe. Midichlorians are microscopic symbionts that reside within the cells of living things and "communicate with the Force". Star Wars creator George Lucas stated that the idea of the midichlorians is based on endosymbiotic theory. The word 'midichlorian' appears to be a blend of the words mitochondrion and chloroplast. The specific epithet, mitochondrii (mi.to' chon.drii. N.L. n. mitochondrium $-i$ a mitochondrion; N.L. gen. n. mitochondrii of a mitochondrion), refers to the unique intramitochondrial lifestyle of this bacterium. 'Candidatus M. mitochondrii' belongs to the phylum Proteobacteria, to the class Alphaproteobacteria and to the order Rickettsiales. 'Candidatus M. mitochondrii' is assigned on the basis of the 16S rRNA (AJ566640) and gyrB gene sequences (AM159536).

'Candidatus M. mitochondrii' has so far only been observed within the ovary of I. ricinus with $100 \%$ prevalence in female ticks. I. ricinus is the main vector of various important human and animal pathogens. This ubiquitous presence suggests that the symbiont plays a role in the biology of female ticks. In addition, 'Candidatus M. mitochondrii' is certainly an important component of the tick microbial community, possibly interacting with the pathogens transmitted by this arthropod. The most striking feature, however, is its unique intramitochondrial localization which could make this symbiont an important model for various 
studies on the biology of this organelle. The presence of various unclassified 16S rRNA gene sequences with high similarity to that of 'Candidatus M. mitochondrii' suggests the existence of a family of related bacteria which has yet to be explored.

\section{ACKNOWLEDGEMENTS}

Support from the Italian Ministry of Universities and Research (MIUR) is acknowledged. N. L. was supported by the Australian Research Council. We thank three anonymous referees for comments on an earlier version of the manuscript. George Lucas kindly granted us permission to base the genus name on the midichlorians.

\section{REFERENCES}

Bandi, C., Anderson, T. J. C., Genchi, C. \& Blaxter, M. (1998). Phylogeny of Wolbachia in filarial nematodes. Proc R Soc Lond B 265, 2407-2413.

Beninati, T., Lo, N., Sacchi, L., Genchi, C., Noda, H. \& Bandi, C. (2004). A novel alpha-Proteobacterium resides in the mitochondria of ovarian cells of the tick Ixodes ricinus. Appl Environ Microbiol 70, 2596-2602.

Black, W. C. \& Piesman, J. (1994). Phylogeny of hard- and soft-tick taxa (Acari: Ixodida) based on mitochondrial 16S rDNA sequences. Proc Natl Acad Sci U S A 91, 10034-10038.

Cole, J. R., Chai, B., Marsh, T. L. \& 8 other authors (2003). The Ribosomal Database Project (RDP-II): previewing a new autoaligner that allows regular updates and the new prokaryotic taxonomy. Nucleic Acids Res 31, 442-443.

Dumler, J. S., Barbet, A. F., Bekker, C. P., Dasch, G. A., Palmer, G. H., Ray, S. C., Rikihisa, Y. \& Rurangirwa, F. R. (2001). Reorganization of genera in the families Rickettsiaceae and Anaplasmataceae in the order Rickettsiales: unification of some species of Ehrlichia with Anaplasma, Cowdria with Ehrlichia and Ehrlichia with Neorickettsia, descriptions of six new species combinations and designation of Ehrlichia equi and 'HGE agent' as subjective synonyms of Ehrlichia phagocytophila. Int J Syst Evol Microbiol 51, 2145-2165.

Fritsche, T. R., Horn, M., Seyedirashti, S., Gautom, R. K., Schleifer, K. H. \& Wagner, M. (1999). In situ detection of novel bacterial endosymbionts of Acanthamoeba spp. phylogenetically related to members of the order Rickettsiales. Appl Environ Microbiol 65, 206212.

Garrity, G. M., Bell, J. A. \& Lilburn, T. G. (2004). Taxonomic Outline of the Prokaryotes. In Bergey's Manual of Systematic Bacteriology, 2nd edn. Release 5.0. New York: Springer. http://dx.doi.org/10.1007/ bergeysoutline

Goddard, J., Sumner, J. W., Nicholson, W. L., Paddock, C. D., Shen, J. \& Piesman, J. (2003). Survey of ticks collected in Mississippi for Rickettsia, Ehrlichia, and Borrelia species. J Vector Ecol 28, 184-189.

Huelsenbeck, J. P. \& Ronquist, F. (2001). MRBAYES: Bayesian inference of phylogenetic trees. Bioinformatics 17, 754-755.

Lee, K. B., Liu, C. T., Anzai, Y., Kim, H., Aono, T. \& Oyaizu, H. (2005). The hierarchical system of the 'Alphaproteobacteria': description of
Hyphomonadaceae fam. nov., Xanthobacteraceae fam. nov. and Erythrobacteraceae fam. nov. Int J Syst Evol Microbiol 55, 1907-1919.

Lewis, D. (1979). The detection of rickettsia-like microorganisms within the ovaries of female Ixodes ricinus ticks. Z Parasitenkd 59, 295-298.

Lo, N., Beninati, T., Sassera, D. \& 13 other authors (2006). Widespread distribution and high prevalence of an alpha-proteobacterial symbiont in the tick Ixodes ricinus. Environ Microbiol 8, 1280-1287.

Mediannikov, O. I., Ivanov, L. I., Nishikawa, M., Saito, R., Sidel'nikov, I. N., Zdanovskaia, N. I., Mokretsova, E. V., Tarasevich, I. V. \& Suzuki, H. (2004). Microorganism "Montezuma" of the order Rickettsiales: the potential causative agent of tick-borne disease in the Far East of Russia. Zh Mikrobiol Epidemiol Immunobiol 1, 7-13 (in Russian).

Murray, R. G. \& Stackebrandt, E. (1995). Taxonomic note: implementation of the provisional status Candidatus for incompletely described procaryotes. Int J Syst Bacteriol 45, 186-187.

Nylander, J. A. A. (2002). MrModeltest. Department of Systematic Zoology, Uppsala University, Uppsala.

Parola, P. (2004). Tick-borne rickettsial diseases: emerging risks in Europe. Comp Immunol Microbiol Infect Dis 27, 297-304.

Parola, P., Cornet, J. P., Sanogo, Y. O., Miller, R. S., Thien, H. V., Gonzalez, J. P., Raoult, D., Telford, S. R. \& Wongsrichanalai, C. (2003). Detection of Ehrlichia spp., Anaplasma spp., Rickettsia spp., and other eubacteria in ticks from the Thai-Myanmar border and Vietnam. J Clin Microbiol 41, 1600-1608.

Sacchi, L., Bigliardi, E., Corona, S., Beninati, T., Lo, N. \& Franceschi, A. (2004). A symbiont of the tick Ixodes ricinus invades and consumes mitochondria in a mode similar to that of the parasitic bacterium Bdellovibrio bacteriovorus. Tissue Cell 36, 43-53.

Sanogo, Y. O., Parola, P., Shpynov, S., Camicas, J. L., Brouqui, P., Caruso, G. \& Raoult, D. (2003). Genetic diversity of bacterial agents detected in ticks removed from asymptomatic patients in Northeastern Italy. Ann N Y Acad Sci 990, 182-190.

Santos, S. R. \& Ochman, H. (2004). Identification and phylogenetic sorting of bacterial lineages with universally conserved genes and proteins. Environ Microbiol 6, 754-759.

Schabereiter-Gurtner, C., Lubitz, W. \& Rolleke, S. (2003). Application of broad-range 16S rRNA PCR amplification and DGGE fingerprinting for detection of tick-infecting bacteria. J Microbiol Methods 52, 251-260.

Strimmer, K. \& von Haeseler, A. (1996). Quartet puzzling: a quartet maximum-likelihood method for reconstructing tree topologies. Mol Biol Evol 13, 964-969.

Thompson, J. D., Gibson, T. J., Plewniak, F., Jeanmougin, F. \& Higgins, D. G. (1997). The CLUSTAL_X windows interface: flexible strategies for multiple sequence alignment aided by quality analysis tools. Nucleic Acids Res 25, 4876-4882.

Zeigler, D. R. (2003). Gene sequences useful for predicting relatedness of whole genomes in bacteria. Int J Syst Evol Microbiol 53, 1893-1900.

Zhu, Z., Aeschlimann, A. \& Gern, L. (1992). Rickettsia-like microorganisms in the ovarian primordia of molting Ixodes ricinus (Acari: Ixodidae) larvae and nymphs. Ann Parasitol Hum Comp 67, $99-110$. 